\title{
The Impact of social media on Learning English Vocabularies
}

\author{
Dr. Lina Fathi Sidig Sidgi
}

Al-Turath University College, Baghdad, Iraq

Received: 06 Jul 2021; Received in revised form: 11 Aug 2021; Accepted: 20 Aug 2021

(C)2021 The Author(s). Published by TheShillonga. This is an open access article under the CC BY license

(https://creativecommons.org/licenses/by/4.0/)

\begin{abstract}
Social media usage has been on the rise in last eight years. Different fields, including business, politics, social events, and education have reaped big from social media. However, the use of social media on language learning has been underresearched. As a result, the sole focus of the research paper was to explore the impact of social media on learning English vocabulary. A systematic review of the literature methodology was utilized. The analysis discovered that social media is an important learning tool. It provides motivation, engagement, and exposure to a wide range of English vocabularies, improving the learner's language skills. As a result, social media has been depicted as a valuable tool that modern-day teachers and curriculum developers should consider in their lesson planning and language acquisition teaching.
\end{abstract}

Keywords-English language, vocabularies, learning, social media, social media platforms, language acquisition, language use, learning language, Facebook, Twitter.

\section{INTRODUCTION}

Social media has become the primary medium of interaction and everyday communication in the modern world. The English language and dialect as the lingua franca of languages is used as the principal language of communication on social media(Al-Smadi, 2013). Social media outlets such as Facebook, Twitter, Twitch, YouTube, Instagram, WhatsApp, and TikTok use the English language as the central mode of communication. The exposure of the English language and terminologies on social media platforms have provided an opportunity for individuals to learn English vocabulary(Alharthi, Bown, \& Pullen, 2020).

According to Lomicka \& Lord (2016), social media platforms have offered an individualized learning environment for individuals striving to acquire English language skills. For instance, it has provided English as a Foreign Language and English as a Second Language learner with an opportunity to improve their vocabulary and use of English words in diverse contexts. Equally, social media provides a platform where students can easily share and discuss their academic materials and coursework. For instance, Facebook has numerous university student groups where learning context is shared and discussed. In the process of discussing, Facebook serves as the medium through which English language vocabularies are shared with the rest of the members. It implies that other than being a medium of communication, social media also holds a position as a resource center where critical learning materials are held.

Social media breaks the distance barriers and embraces diversity and connection between individuals from different regions. Students are exposed to interactions involving diverse learners from all over the world. It implies that through the utilization of social media, learners across the world are given a chance to advance and improve their English language vocabulary learning processes (Monica-Ariana \& Anamaria-Mirabela, 2014). For instance, a student in a remote African country such as Congo has the prospect of learning a significant amount of English language vocabulary through interaction with American or UK-based learners who use English as their first language. More significantly, it provides the opportunity for the learner to improve their writing and spelling, as they have a clear observation of the context in which different words are applied (Monica-Ariana \& Anamaria-Mirabela, 2014). 
In the process of enhancing individual English vocabulary usage, learners have been relying on webbased learning platforms or CD-based resources. However, a study by Khan, Ayaz, \& Faheem (2016) revealed that social media platforms are more foundation and sustainable in improving one's ability to learn an English vocabulary and improve the overall ability to utilize the world. The diversity of English language users on social media provides a good learning environment for ESL and EFL learners to understand the meaning and context of different words. For example, Twitter has been fundamental in promoting English language vocabulary build-up for ESL learners. For instance, during the Russian invasion of Ukraine, different news reports on social media provide a wide range of English vocabularies such as 'shelling' were commonly used (Twitter, 2022).

Introducing such new words to English as a Second Language learners offers a crucial opportunity to enhance one's vocabulary usage and understanding. Irrespective of the general understanding of the impacts of social media on learning English vocabulary, the topic area has not been adequately explored. Critical research gaps exist regarding the true influence of social media and its influence on the English language learning and enhancement processes. Resultantly, the primary focus of the research paper is to deeply explore and evaluate the impact of social media on learning English vocabularies and how well learners can utilize social media to enhance their English language learning and vocabulary reservoir.

\subsection{Statement of the Problem}

As the world evolves due to globalization and the fast development in technology, so does language use. Advancement in technology has bridged the communication gap by introducing social media platforms and a convenient way of interacting and sharing information. In the interaction process, key verbs and English phrases are introduced to English learners. The social media platforms create an environment to engage, interact, and challenge English learners with new vocabularies and word usage. It implies that the classical structure and approach to the English language have evolved from traditional classroom learning to a more socially-embedded form of English vocabulary learning.

Irrespective of the opportunities social media presents, English language learners do not have clear guidance on the actual usage of the prospects presented by media in learning English vocabularies. As a result, the research paper will provide a clear and concise exploration of the impact and influence of social media on learning English vocabularies and how well the learners could identify the opportunities to enhance their learning and improve English vocabularies usage.

Additionally, different social media platforms present unique educational pathways for both English as First Language, and English as Second Language learners. However, without the appropriate support and guidance on utilizing social media for language learning, it becomes challenging to enhance one's vocabulary use abilities. As an instrumental tool for language learning, social media creates an avenue for knowledge sharing, interaction, and communication. Though, it has an intense form of ubiquity that could affect how learners acquire and utilize learned vocabularies. As a result, the study will seal the gap by exploring how well learners could use the symbols, pronunciation tools, web-based translation engines, and symbols to understand how to utilize a vocabulary in different contexts. In its entirety, the research paper will evaluate vocabulary learning on social media, citing the principal role and impact of social media in the learning process. To completely seal the gap, it will also provide recommendations for ESL and EFL students on how well to utilize social media and reap the benefit of learning from its resources and interaction platforms it provides.

\subsection{Research Question, Aim, and Objectives}

\subsubsection{Research Question}

Does the use of social media platforms enhance the learning of English language vocabulary?

\subsubsection{Research Aim}

The primary aim of the research is to explore the impact of social media on learning English language vocabulary.

\subsubsection{Research Objectives}

I. To investigate the impact and influence of social media usage on English language vocabularies learning.

II. To examine how well ESL and EFL learners could utilize the opportunities presented by social media in enhancing their English vocabulary learning.

\subsection{Significance of the Study}

As the main mode of communication, social media platforms have proved to be effective tools for sharing information and learning a language. Diverse research studies have argued that social media provides a unique learning environment for English language learners to improve their vocabulary and language usage. While considering the lessons learned from the Covid-19 and the impact of technology in bridging learning gaps, learning on social media has shown to be more effective when compared to a traditional classroom setup. As a result, the 
research is important as it will outline the impact of social media on learning English vocabulary. More significantly, it will provide guidelines on how ESL and EFL learners can maximize the opportunities served by social media platforms to enrich the English language vocabulary. For instance, it will showcase how English language learners can utilize social media platforms as a tool for improving their vocabulary enlargement, pronunciation, and word use in different contexts.

\subsection{Theoretical Framework}

The research paper's exploration is founded on the Schema theory of vocabulary learning and acquisition. In English language learning, learners with limited prior knowledge about English vocabularies and their usage have challenges in learning and adopting new phrases and words. A study by McVee, Dunsmore, Gavelek (2005)showed that when learning new vocabularies, the lack of schema due to limited reading and exposure to the English language proves a major challenge in learners striving to develop their English vocabularies. Resultantly, the theoretical framework argues that the learner's background knowledge and exposure serve as scaffolding to encode new information from a particular text. The theory suggests that as learner experiences new words and vocabularies grow, it becomes easy for them to use the words in different contexts. The theory aligns with the research focus. It provides critical insights into why exposure to social media interaction expands the learners' English language vocabularies adoption and usage in diverse communication contexts. The continued exposure to the world creates a good environment for improving the spoken use of words and application in both social and written contexts.

\subsection{Scope and Limitation of the Study}

Regarding the scope, the research paper will predominantly focus on the impact of social media platforms on learning English language vocabulary. It will not feature other Web 2.0 or Web 3.0 internet-based platforms used to enhance English vocabulary learning. Additionally, the study is limited to English vocabulary learning linked to American and British English language phrases and terms. The core reason for choosing the two zones is based on the fact that English is the official language. Equally, they are an important source of quality vocabularies and English language enhancers that make it possible for ESL and EFL learners to learn and expand their English language usage.

\section{LITERATURE REVIEW}

In the contemporary learning environment, social media language learning (SMLL) has been adopted an innovative strategy for teaching and learning languages and vocabularies. Curriculum planners integrate social media to enhance vocabulary learning and usage by learners. The strategy involves encouraging students to develop social media groupings, communicate, interact, and share information with their peers. In the process, they are better placed in the acquisition of English language skills while enhancing their vocabulary bank. Consequently, the literature review section will evaluate diverse literature sources, including articles, journals, and books, to understand the impact of social media on learning English vocabulary.

\subsection{English Vocabularies and Social Media}

According to Swan (2017), learning a language is founded on a learner's ability to learn, adapt, and use different vocabularies. In ESL and EFL, vocabulary learning is critical in powering their language acquisition skills, usage, and enlargement. Vocabularies work as a vital component of language skills as it helps in connecting the learner's ability to read, write, listen, and speak to a given language. Equally, its vocabularies provide the foundation the foundation through which the learner can utilize the acquired language in different contexts. It implies that the learner will be limited in their contexts, engagements, and interactions without a well-founded vocabulary. Among the ESL and EFL learners, the student's failure or success in language acquisition is determined by the magnitude of vocabulary and acquisition that the learner possesses. Critically, vocabularies are a vital ingredient in language usage among learners, and it creates the gateway through which the learner's success in interaction and language usage are aligned.

To effectively bridge the exposure between the traditional classroom and the modern world of Internetbased interaction, social media lays the platform for learners to advance their vocabulary learning and enlargement. Social platforms such as Twitter, Facebook, YouTube, and Twitch, classified as social networking platforms, create an environment that virtually assists learners in enlarging their vocabularies. Through social media, learners can access large amounts of information, encode, and share their experiences with others. In the process of sharing and processing data on social media, learners are exposed to a variety of vocabularies that are critical in building the learner's language skills.

According to Sebah Al-Ali (2014), English vocabulary learning is influenced by the magnitude of exposure and the frequency of use in different contexts, forums, and situations. Social media provides a flexible environment where learners are exposed to different 
vocabularies without being coerced into learning. For instance, articles shared on social media such as Instagram expose the learner to the need to read new content. In reading either for fun or pleasure, the learner can learn new vocabulary. After reading the article, the learner may be prompted to give feedback or comment on the article's contents. In so doing, the exposure indirectly forces the learner to internalize and understand the content shared to be in a position to make a quality response. Critically, the entire cycle of interacting, reading, socializing, and offering reviews within the social media platform exposes the learner to hands-on skills geared towards language acquisition and vocabulary enlargement.

In word use and context, social media platform such as Twitter plays a critical role. Twitter social platform has a limit of 280 characters, and it implies that the social media platform strives to guarantee a clear and concise message purposed for quick reading. By encouraging a limited number of words in passing a message, the social media platform creates a good opportunity for learners to easily learn the context and meaning in which different words fall. The differentiated word usage on social media serves as an opportunity for the learner to expand, experiment, and develop their language use vocabularies.

Gibbins \& Greenhow (2016)emphasized that social media also impacts learning English by accompanying words with visuals. On social media, objects or pictures are labeled or described using words. The approach takes an activation strategy where a new English learner can easily understand what different situations mean in pictures and the specific words to utilize in offering a description. For example, YouTube provides an option for a viewer to activate video captions. The captions help in transcribing the words described by the speaker into written words. Other than bridging the process of understanding the context in which words are used, it creates an avenue where the learner acquires the spelling and the connective words to utilize while using the particular word.

Irrespective of the positive impact of social media in enlarging a learner's vocabulary reservoir, there are situations where it might adversely influence their language acquisition skills. For example, social media is well known for its rapid use of jargon and internet slang that is not grammatically applicable. For instance, words such as LOL (Laugh out Loud), IYKYK (If you know, you know), or BTW (by the way) have the potential of affecting an ESL learner's English vocabulary retention and use. Social media's positive and negative impact on vocabulary acquisition calls for guidance in the context in which vocabularies are applicable and what makes them grammatically appropriate.

Considering that English is the primary language used in the modern transactional world, students exposed to social media have an increased potential to communicate and succeed in the classroom compared to the rest. Social media platforms such as Twitter are more of a word-based platform when compared to Facebook, which has more pictures. Learners can utilize the learned vocabularies in different contexts through intense exposure to words, phrases, and verbs. An analysis by Gaytan (2013) compared vocabulary acquisition between students in a traditional classroom and those exposed to a social media platform. During the study, some participants were exposed to social media while others in normal classroom setup. The learners in the controlled traditional classroom were exposed to the use books, simple explanations, pictures, and flashcards. After two months of study, the research showed that learners exposed to social media have an enlarged vocabulary base compared to the rest. The researcher revealed that social media integration in the learning process improved vocabulary usage, writing, and language use skills.

Additionally, Derakshan \& Hasanabbasi (2015)highlighted that social media offers a free interaction environment where users participate in realtime, real-life, and relevant conversations. The virtual engagement offers a good chance for the language learner to reduce their anxiety, pressure, and improve their language skills. Peer discussion, commenting, and reviews on social media motivate the learner to participate in reallife conversations. In real-life conversations, they can utilize the words learned in social media in different contexts. Analytically, it implies that social media platforms such as Facebook and Twitter function as an important English learning tool. Other than offering the learner the opportunity to acquire and stabilize their language use, it provides a chance to collaborate and test the usage of different wordings. Social media creates a virtual room where an ESL can learn new words and vocabulary from peers without meeting native speakers in real-time.

The schema theory argued that for a student to acquire and be better placed in using the vocabularies, continuous exposure to the conversations and interactions generating the new words must be generated. Derakshan \& Hasanabbasi (2015)noted that social media continuously generates news words and conversations as the world evolves and experiences new events and situations. Continuous exposure is vital in the learner's language learning processes. For example, before Covid-19, ESL 
students were not used to words such as 'cessation of movement,' 'lockdowns,'"mask-up, 'and 'vaccination.' However, learners can learn through social media interactions and add the new words into their vocabularies. In entirety, it shows that other than enhancing the vocabulary structure of the new learners, social media educates and empowers the new learners with new experiences, which are critical in building their language usage approaches.

Similar to inclusive classrooms, social media platforms integrate native and non-native speakers into interaction, socialization, and discussions. In socialization, the native speakers provide important words and vocabulary to the non-native speakers. The new words learned help motivate more engagement between the learners, which creates a better atmosphere for adopting new words. Moreover, combining visuals and videos into the interaction provides insights and vocabulary build-up for non-native speakers. Critically, social media is an important learning tool for students working on developing their vocabulary. Considering that the learning environment is voluntary and socialized, the learner learns without a feeling of pressure from peers. The exposure and the learning process are naturalized, hence providing a great opportunity to understand the context in which different words are utilized.

According to Al-Rahmi \& Othman (2013), motivation and self-drive in the learning process is critical ingredient for successful learning. Social media impacts learners' confidence, motivation, and positive attitude towards personal improvement in vocabulary and language use skills. Engagements on social media offer a positive attitude and the motivation to integrate different vocabularies into the communication. The integrated vocabularies originate from reading different texts, articles, messages, or events shared by peers worldwide. For example, the current issue of the Russian invasion of Ukraine provides an important opportunity for learners to retrieve and acquire vital vocabulary to use in sharing their sentimental understanding of global issues. Through interaction with the global issues and topics on social media, learners are kept updated with new trending words and free access to a large pool of new vocabularies and phrases. The engagement, sharing, and participation in social media activities imply that the learner's language will improve while their language base will be extended without having to read more books. In totality, it is evident that social media exposes the learner to a wide variety of information which is vital in enhancing language acquisition and improvement in the overall language usage and skills.
In summary, the literature review has shown that vocabulary learning is a vital aspect of language acquisition and usage. For ESL and EFL learners, mastering vocabularies can be a challenge. However, the socially-embedded environment offered by social media exposes the student to a wide range of information that is crucial in providing an important vocabulary pool. On social media, the learner acquires using and integrating the new word in different contents. The exploration affirms that social media improves the learner's language proficiency, provides an environment for wide reading, and exposure to both simple and complex texts, leading to better vocabulary development.

\section{METHODOLOGY}

The research adopted a systematic review methodology for the study. The core reason for choosing a systematic review methodology is that it provides a good opportunity to utilize peer-reviewed journals and resources to retrieve critical information linked to the study topic. In order to understand the impact of social media on learning English vocabularies, the researcher was required to comprehend and interpret the evidence offered by different publications related to the topic. As a result, a qualitative research design was adopted to help evaluate and analyze the selected systematic reviews to help answer the research question and achieve the goals and objectives of the research(Creswell \& Creswell, 2020).

The researcher relied on secondary data retrieved from journals, articles, books, and peer-reviewed publications to answer the research question regarding the type of data used. The literature review was developed and planned to reduce biases and eliminate all irrelevant and low-quality studies. For instance, all articles older than ten years were not considered for the review. Equally, the selected resources were all published in English and peerreviewed. The approach provided a good opportunity to ensure that only quality research materials were utilized in the analysis. Concerning data analysis, the systematic review focused on journals that contained important keywords linked to social media's impact on learning English vocabularies. In so doing, it was easy to retrieve high-quality ideas from peer-reviewed sources and adequately answer the research questions. Once a particular peer-reviewed journal was identified, information was extracted to help answer the research question. Then, any available biases or limitation in the study was assessed to ensure that it does not contradict the aim and focus of the study. The selected methodology provided a good opportunity for the research to seal all the study gaps, and understand the core impact of social media 
on language acquisition and English vocabulary development.

\section{FINDINGS AND DISCUSSION}

The systematic review of literature sources has discovered that exposure to social media platforms has a positive impact on the capability of learners to adopt and add up their English vocabularies. However, it has also emerged that social media usage by ESL and EFL learners without proper guidance may distort their English language skills, vocabulary usage, and grammatical challenges due to the inclusion of jargon in their conversations. Nonetheless, the benefit of social media on learning English vocabulary outweighs the adverse effects of the same. Among the key influences of social media in the acquisition, use, and learning of English vocabularies include:

\subsection{Social Media Motivates Students to Learn}

Social media keeps the learners engaged, participative, and motivated to learn. On social media, learners are continuously exposed to content that prompts and triggers them to continue reading. In the process, they can sharpen their reading skills, listening skills, writing skills, and at the same time improve their vocabulary understanding and usage. Different researches showed that learners exposed to social media, especially Facebook and Twitter, scored high in vocabulary post-test when compared to learners in the traditional classroom. It affirms that social media helps improve and enhance the learners' vocabulary knowledge. Other than increasing their vocabulary makeup, social media offers an opportunity for learners to have clear meaning and usage of different words in particular content. As a result, social media lays the foundation through which the language skills of individuals are virtually improved.

\subsection{Social Media and Incidental Learning of English Vocabularies}

Learning happens in situations where the learner is exposed to repetitive information exposure. Equally, the student must role play in the learning process to help get hands-on knowledge and understand how different words and phrases are used. On social media, the user's mind is focused on other things such as pictures, events, or videos being streamed. In the process, they are exposed to texts and articles that need to be read to have a clear understanding of what is unfolding. The user is exposed to vocabularies and communicative technics through the incidental participation to be part of the group. Normally, ESL learners rely on incidental and guessing the meaning of language contents to create a vocabulary bank while on social media.

As initially explored, once a new word is learned, the learner may try to use it in the comment section or feeds within the social media platform. They may use it in their daily communication and interaction with peers in other conditions. By connecting the learned word to personal experiences and utilizing it in their daily interactions, the learner can adopt and utilize the vocabulary as their own. In the process, they are better placed in building a stronger language that reflects their needs and social practices. The extensiveness of social media provides an implicit and explicit environment where learners can easily find new words, experiment with them, and consolidate their usage in their daily interactions and engagements.

Additionally, social media offers a platform where language learners have the independence of learning based on their speed and abilities. The self-study ability offered on social media creates a good environment for guaranteed success in learning and using the adopted vocabularies. Also, exposure and peer-to-peer learning increase the potential for experimenting with the words until the user is comfortable with them. Since social media access is done at the user's disposal, learning is flexible and unforced. The learner has enough time to listen, read, and practice the spelling and application of the learned new words. The self-directed process creates a smooth avenue where the learner can easily remember the learned words and the contexts in which the phrases and words are applied. In its entirety, social media acts as a critical learning tool for students striving to build and enhance their language. The enlarged range of vocabularies and interactions on social media creates a better platform for word structural and functional usage in the learners' communication channels(Nikbakht \& Boshrabadi, 2015).

\subsection{Social Media and Linguistic Proficiency}

Linguistic proficiency reflects the magnitude of how well a particular learner has mastered a language. Social media plays a critical role in improving a learner's linguistic proficiency by enhancing their syntax, semantics, vocabulary, and word receptive and expressive language skills. Social media enhances linguistic proficiency by improving learners' understanding and exposure to vocabulary. Equally, it improves learners' grammatical competence by exposing them to a field where English is purely used as the main language of communication. The student's English proficiency is improved following the guidance and support offered by native English speakers(Bicen, \& Sadikoglu, \& Sadikoglu, 2015). It is evident that social media is vital in vocabulary 
building, vocabulary usage, and grammatical competence hence enhancing the learner's English language skills.

\section{CONCLUSION}

The exploration has discovered that learners are exposed to new words and vocabularies through social media. The interactions, discussions, and forums present on social media play a vital role in getting English vocabulary. Besides offering access to vocabularies, it creates an avenue for learners to practice and engage with their peers using the learned vocabularies. Additionally, the flexibility on social media and the independence of use enables a learner-controlled learning process. The learner takes time to build motivation and interest in given areas. They are exposed to content that prompts them to read or listen to videos, audio, or podcasts in the process. The exposure offers a greater opportunity to understand the diversity of vocabularies and the specific manner in which they need to be applied in different communication contexts.

Compared to the traditional classroom, social media offers more confidence for learners to interact with complex vocabularies. The peer learning environment on social media creates the avenue through which the learner is motivated to try out new things without feeling judged by their peers. Such a self-regulated learning environment best promotesthe generation of new ideas as the learner interacts with vocabularies. In so doing, they are better placed in improving their language skills. Therefore, inclusive classroom educators need to embrace new technologies and social media in language teaching; the approach will improve the acquisition of new vocabularies and enhance the learners' ability to use the English language most appropriately.

\section{REFERENCES}

[1] Alharthi, M., Bown, A.,\& Pullen, D. (2020). The Use of Social Media Platforms to Enhance Vocabulary Development in Learning a New Language: A Review of the Literature. Arab World English Journal (AWEJ) Special Issue on CALL (6). 318 -331.DOI: https://dx.doi.org/10.24093/awej/call6.21.

[2] Al-Rahmi, W. M. \& Othman, M. O. (2013). Evaluating Student's Satisfaction of Using Social Media Through Collaborative Learning in Higher Education. International Journal of Advances in Engineering \& Technology. 6(4), p.1541-1551.

[3] Al-Smadi, S., (2013) The role of using Facebook in improving English, TOJSAT: The Online Journal of Science and Technology, Volume 3, Issue 1.

[4] Bicen, H., \& Sadikoglu, S., \& Sadikoglu, G. (2015). The impact of social networks on undergraduate students learning foreign language. Procedia: Social and Behavioral Sciences, 186, 1045-1049.

[5] Creswell, J. W., \& Creswell, J. D. (2020). Research design: Qualitative, quantitative, and mixed methods approaches. Thousand Oaks, California: SAGE Publications, Inc.

[6] Derakshan, A. \& Hasanabbasi, S. (2015). Social Networks for Language Learning. Theory and Practice in Language Studies, 5(5), p.1090-1095.

[7] Gaytan, J. (2013). Integrating social media into the learning environment of the classroom: Following social constructivism principles. Journal of Applied Research for Business Instruction, 11(1).

[8] Gibbins, T., \& Greenhow, C. (2016). students' out of school writing practices in an educational Facebook application. In I. R. Association (Ed.), Social Media and Networking: Concepts, Methodologies, Tools and applications. p.10111027.

[9] Khan, I. U., Ayaz, M., \& Faheem, M. (2016). The role of social media in development of English language vocabulary at university level. International Journal of Academic Research in Business and Social Sciences, 6(12), 590-604. DOI: 10.6007/JJARBSS/v6- i11/2444.

[10] Lomicka, L., \& Lord, G. (2016). Social networking and language learning. In F. F. L. Murray (Ed.), The Routledge handbook of language learning and technology (pp. 255268). New York: Routledge.

[11] McVee, M.B.; Dunsmore, K.; Gavelek, J.R. (2005) Schema Theory Revisited. Rev. Educ. Res. 2005, 75, 531-566.

[12] Monica-Ariana, S., \& Anamaria-Mirabela, P. (2014). The impact of social media on vocabulary learning case studyFacebook. Annals of the University of Oradea, Economic Science Series, 1(2), 120-130.

[13] Nikbakht, E., \& Boshrabadi, A. M. (2015). Analyzing the potential of social networking sites on EFL learners' vocabulary mastery: A situated-learning approach. Theory and Practice in Language Studies, 5(8), 1635-1641. DOI: 10.17507/tpls.0508.13.

[14] Sebah Al-Ali. (2014). Embracing the Selfie Craze: Exploring the Possible Use of Instagram as a Language Learning Tool. Issues and Trends in Educational Technology, 2(2), p.1- 16.

[15] Swan, K. (2017). Gaining Perspective: Social Media's Impact on Adolescent Literacy Development, Education and Human Development Master's Theses, 767, p.1-41. 